\title{
Muscular and functional performance measurement is reduced in elderly after total hip arthroplasty: an observational study
}

\begin{abstract}
Objectives: To evaluate the functional and isokinetic muscular performance of the elderly, after total and unilateral hip arthroplasty due to hip osteoarthritis (OA).

Methods: Twenty elderly with total hip arthroplasty (THA) and a matched control group were included. Isokinetic muscular performance (Biodex) and gait speeds were measured (GAITRite $\left.{ }^{\circledR}\right)$. THA group completed the Western Ontario and McMaster Universities Osteoarthritis Index (WOMAC) questionnaire.

Results: There were no differences between non-operated and operated legs. Significant differences between groups were evident for hip abduction $(\mathrm{p} \leq 0,008)$, knee flexion $(p \leq 0,003)$ and knee extension $(p \leq 0,003)$ movements. At the fast gait speed, statistical significant effects between groups were observed $(\mathrm{THA}=1,71 \mathrm{~m} / \mathrm{s}$, Control $=1,96 \mathrm{~m} / \mathrm{s}, \mathrm{p}=0,017)$. THA elderly group showed lower scores in pain $(6 \pm 11,85)$, stiffness $(8,12 \pm 15,39)$ and function $(9,12 \pm 20,45)$ in WOMAC domains.
\end{abstract}

Conclusion: Years after THA surgery due to OA, the elderly were not restored to the same levels of strength and power of the hip and knee muscles, as compared with a matched control group

Keywords: aged, osteoarthriti, hip, arthroplasty, muscle strength, gait
Volume 2 Issue 3 - 2017

\author{
Viviane Santos Borges,' João Marcos \\ Domingues, ${ }^{2}$ Rosângela Corrêa Dias, ${ }^{2}$ Rita \\ de Cássia Guedes ${ }^{3}$ \\ 'Physiotherapist in Physical Therapy Department, Universidade \\ de Itaúna, Brazil \\ ${ }^{2}$ Associate Professor in Physical Therapy Department, Federal \\ University of Minas Gerais UFMG, Brazil \\ ${ }^{3}$ Physiotherapist in Physical Therapy Department, Federal \\ University of Minas Gerais UFMG, Brazil
}

Correspondence: Viviane Santos Borges, Physiotherapist in
Physical Therapy Department, Universidade de Itaúna, Brazil, Tel
(55) 3732412085 , (55) 37999387269, Email visb.edu@gmail.com

Received: November 09, 2017 | Published: December 0I, 2017

\section{Introduction}

The continuum growth of elderly and the increase in expectation of life have as consequences greater prevalence and incidence of chronic degenerative diseases. ${ }^{1,2}$ One of the most prevalent and common is the osteoarthritis. ${ }^{3-6}$ The hip joint is frequently affected by this condition, and total hip arthroplasty (THA) is the recommended treatment in advanced stages of the disease. ${ }^{7}$ Due to the chronicity and demand for constant care of the OA, its treatment aims at controlling patients sintomatology; however, in advance stages of the disease noninvasive treatments as medications and physical rehabilitation have limited value, and THA is recommended after rigorous criteria assessment. ${ }^{6,8-13}$ This surgery is associated with many undesirable risks and consequences. ${ }^{8,14,15}$

The aging process is accompanied by important skeletal muscle alterations as reduction in muscle cross-sectional area and decline in muscular performance at slow and fast angular speeds. ${ }^{16,17}$ With surgery interventions, this process gets even worse. ${ }^{18}$ The combination of these adverse effects regarding the reduction in muscular strength and the accumulative effects of OA and THA need to be more explored. This way, the purpose of this study was to evaluate the functional and isokinetic muscular performance of the aged after eight months to five years after total and unilateral hip arthroplasty due to hip osteoarthritis.

\section{Methods}

\section{Study design and ethics aspects}

An observational, cross-sectional study was performed. This study was approved by the Universidade Federal de Minas Gerais
Ethics Committee (ETIC647/08) and by the Hospital Governador Israel Pinheiro Ethics Committee HGIP-IPSEMG (CEP336/08). All participants were informed and consented to participate.

\section{Participants}

The THA elderly were selected using convenience sampling, through an electronic database supplied by the Hospital. The control group, matched by sex, dominant limb, age and Body Mass Index (BMI), was also selected by convenience sampling from community. The sample size calculation was based on Bertocci et al. ${ }^{19}$ study's information from 2004. Considering a two-tailed analysis and a significant level of $\alpha=0.05$ and a statistical power of 0.80 , it was established a sample size of 40elderly, 20 in the THA group and 20 in the control group. ${ }^{20}$

The eligibility criteria included: elderly aged 60 years or more who underwent unilateral primary total hip arthroplasty due to hip OA, using a cemented prosthesis and a posterolateral surgical approach. The elderly had to be community residents and able to ambulate without assistive devices. Subjects were excluded if they had uncontrolled cardiorespiratory diseases; neurological diseases; balance problems; other disabled osteomuscular diseases; referred hip or knee pain that exceeds three in the visual analog scale (VAS) ${ }^{21}$ hip and knee range of motion (ROM) limitation; presence of cognitive impairment assessed by Mini-Mental State Exam(MMSE) ${ }^{22}$ instrument; accumulated at least 30 minutes of physical activity on most days of the week ${ }^{23}$ and in the last three months, including participation in a physical training program; had undergone other orthopedic surgery in the lower limbs or lumbar spine. The same inclusion/ exclusion criteria were used for the control group, with the exception of undergoing THA. 


\section{Instruments}

For investigation and data collection, the volunteer filled in a form (to collect demographic and clinic data). The isokinetic dynamometer Biodex System 3Pro ${ }^{\circledR}$ (Biodex Medical Systems Inc., Shirley, NY, USA ${ }^{24}$ was used to assess dynamic muscular performance of specific muscle groups. The use of Biodex for evaluating hip and knee musculature performance is study protocol is considered an acceptable measurement tool with good reliability coefficients above $0.87 .{ }^{1}$ The GAITRite ${ }^{\circledR}$ System (MAP/CIR INK, Haverton, PA, USA). ${ }^{25}$ an electronic walkway, pressure sensitive electronic surface of 5,6 x 0,90 $\mathrm{m}$, was used to measure the spatiotemporal parameters of gait (selfselected and maximal gait speeds). This carpet includes a series of sensors activated by mechanical pressure. ${ }^{25}$ The Western Ontario and McMaster Universities Osteoarthritis Index (WOMAC), was used to measure the health status of the THA group. ${ }^{26,27}$ The WOMAC is a multidimensional instrument, specific for patients with osteoarthritis of hip or knee following total arthroplasty. It is composed of 24 items grouped into three domains: pain, stiffness and physical function. ${ }^{27}$ The data were standardized to a range of values from 0 to 100 , where 100 represents the worst health status possible. ${ }^{13,27}$ In the present study, the valid and reliable Brazilian version of WOMAC was used. ${ }^{26}$

\section{Procedures}

Before the beginning of data collection, intra-examiner reliability of isokinetic measurements were established. All measurements were always done by the same investigator. The intra-examiner reliability was assessed with a group of 10 elderly, aged 60 to 81 years $(68,1 \pm 7,62$ years). The intra-examiner reliability of the Biodex measurements was estimated by calculating the intraclass correlation coefficient (ICC). The peak torque (Nm) was the variable chosen to be analyzed. The elderly were tested on two separate days, at the same time of day. ${ }^{4}$ The ICC for hip abduction and adduction movements ranged from 0.88 to 0.96 ; for knee flexion and extension movements it ranged from 0.91 to 0.98 and for hip flexion and extension movements the ICC ranged from 0,91 to 0,98 After the identification of THA elderly, through the electronic database, one investigator contacted the person by telephone. In this first contact, after receiving information about the study, patients interested in participating were selected according to some inclusion/exclusion criteria, preventing people who do not fit these initial criteria from coming to the laboratory unnecessarily, because the majority of them did not live in the city where the study was conducted.

After the certification of inclusion, the subjects were invited to participate dressed in comfortable clothes and footwear. They signed the informed consent form prior to the muscular and functional analyses. Initially, subjects performed gait tests at two speeds: selfselected ("walk at a pace that is comfortable for you") and fast ("walk at a pace that is faster than you would normally walk, without running"). The number of trials was determined in a pilot study. Six trials were recorded for each subject and for each speed, and the average was used for subsequent analysis. ${ }^{28}$ Participants started and finished walking 2 meters before and after the mat, respectively, to allow for acceleration and deceleration. ${ }^{29,30}$ The order of the gait speed tests was not randomized, starting with the self-selected speed. The spatiotemporal parameters analyzed (mean of self-selected and maximal velocity normalized by the leg length) were calculated by the GAITrite ${ }^{\circledR}$ software and then were processed by the investigator.
Following the gait speed tests and before the muscular performance measurements, the participant performed at least five minutes of warm-up on a treadmill. ${ }^{31}$ Before each test on the dynamometer, the volunteer performed two familiarization trials of three maximal repetitions for each movement and angular speed ${ }^{32}$ to minimize the variability of measurements (coefficient of variability) and to get the sincerity of effort during isokinetic testing. The non-operated side was tested first to increase the subject's comfort with the procedure. .,17,33 $^{4}$ For the control group, the test was initiated with the dominant. ${ }^{24}$ In the present study, the testing positions were constant, to minimize testing duration and limit fatigue. ${ }^{17}$ The first movements performed were knee extension and flexion, keeping the participant comfortable, because this joint is free of prosthesis. Then, the hip movements were tested: abduction/adduction and flexion/extension. During the tests standardized verbal encouragement was given to ensure the maximal force. $^{32,34,35}$

Concentric isokinetic movements were tested in both limbs and a two-minute rest interval was allowed between the two angular speeds. The variables peak torque and maximal work normalized by body mass at a low angular speed $\left(60^{\circ} / \mathrm{s}\right)$, and the peak torque normalized by body mass and the average power at fast angular speeds $(120 \% \mathrm{~s}$ e $180^{\circ} / \mathrm{s}$ ) were considered for analyses. Concentric isokinetic knee flexion and extension movements were assessed at a preset angular speed of $60^{\circ} \mathrm{s}$ (five repetitions) and $180 \% \mathrm{~s}$ (15 repetitions) $)^{21}$ and over a range of motion of $85^{\circ}$, from $5^{\circ}$ to $90^{\circ}$ of knee flexion. The subject was positioned in the chair of the dynamometer with an $85^{\circ}$ of seatback position. The knee joint axis was aligned with the mechanical axis of the dynamometer and the pad was placed just superior $(3 \mathrm{~cm})$ to the lateral malleolus.

Concentric isokinetic hip abduction, adduction, flexion and extension movements were assessed at a preset angular speed of $60 \% \mathrm{~s}$ (five repetitions) and at $120 \% \mathrm{~s}$ (15 repetitions).(19;31;35;36) Because of its functional relevance, the standing weight-bearing posture was chosen for the assessment of the hip measurements. The elderly were positioned in standing by using a especially built adjustable stabilization frame. ${ }^{37,38}$ As the participants were unable to consistently generate adduction torque at $120 \%$, this movement at this angular velocity was not considered for analysis.

For the hip adduction and abduction movements it was used a range of motion of $0^{\circ}$ to $30^{\circ}$, starting from neutral position. ${ }^{35}$ The mechanical axis of the dynamometer was aligned through an imaginary line crossing the anterior superior iliac spine. ${ }^{24,35,37}$ The pad was positioned just superior to the popliteal fossa, nine centimeters of the knee joint interline. ${ }^{35}$

For hip flexion and extension movements it was used a range of motion of $0^{\circ}$ to $60^{\circ}$, starting from neutral position. ${ }^{35}$ The greater trochanter was aligned superior and anterior with the mechanical axis of the dynamometer and the pad was placed just superior to the popliteal fossa. ${ }^{35,37}$ For the control group, bilateral measures were performed, but only the matched control limb was considered for analyses. ${ }^{4}$ All assessed parameters of the study were calculated by the dynamometer software and were recorded on a standard output provided by the system. Before the calculations, the options of filter and windowing were selected. The gravity correction was obtained before each test and the calibration of the Biodex dynamometer was performed according to the specifications of the manufacturer's service manual. 


\section{Statistical analyses}

The values were expressed as mean, standard deviation, ranges and proportion. The normality of distribution was assessed using the Shapiro-Wilk test. Independent $t$ tests and repeated ANOVA measures with three levels and pre-defined contrasts were used. Data without a normal distribution were analyzed using Wilcoxon signed-rank test and Friedman test. These tests were used to assess the differences between operated versus non-operated limbs and differences between groups, respectively. The Pearson's correlation coefficient was used to quantify correlation between time of postoperative and maximal work normalized by body mass. An alpha level of 0.05 was set for all statistical tests of significance. Statistical analyses were performed using Statistical Package for Social Sciences (SPSS), Version 15.0.

\section{Results}

The sample consisted of 20 THA elderly and a control group of 20 subjects without arthroplasty, matched by gender, age, BMI, and dominant limb. Table 1 shows descriptive characteristics of both groups regarding anthropometric data, age, gender, comorbidities and level of education, and information about the surgery for the THA group. There were no differences between groups $(p>0.05)$ regarding demographic and anthropometric data. Table 2 summarizes the results of WOMAC scores, presented by domains.

Table I Clinic and demographic subject characteristics

\begin{tabular}{|c|c|c|c|c|c|}
\hline \multirow{2}{*}{$\begin{array}{l}\text { Variables } \\
\text { Age (years) }\end{array}$} & \multicolumn{2}{|c|}{ THA group $(n=20)$} & \multicolumn{2}{|c|}{ Control group $(n=20)$} & \multirow{2}{*}{$\begin{array}{l}\mathbf{p} \\
\mathrm{p}=0.822^{*}\end{array}$} \\
\hline & $70.10(5.77)$ & $60-83$ & $70.50(5.39)$ & $60-82$ & \\
\hline BMI $\left(\mathrm{Kg} / \mathrm{m}^{2}\right)$ & $28.11(3.78)$ & $21.3-37.7$ & $28.43(3.45)$ & $23.2-36.2$ & $\mathrm{p}=0.779 *$ \\
\hline Body Mass (kg) & $75.54(\mid 3.06)$ & $54.5-98.95$ & $75.49(10.24)$ & $57.9-90.40$ & $\mathrm{p}=0.98 *$ \\
\hline Gender - male (n) & 11 & & 11 & & \\
\hline \multicolumn{6}{|l|}{ \#Comorbidities } \\
\hline None & $\mathrm{I}(5 \%)$ & & $I(5 \%)$ & & \\
\hline One & $15(75 \%)$ & & $17(85 \%)$ & & \\
\hline Two or more & $4(20 \%)$ & & $2(10 \%)$ & & \\
\hline \multicolumn{6}{|l|}{ Education } \\
\hline Illiterate & $\mathrm{I}(5 \%)$ & & - & & \\
\hline I - 4 years & $4(20 \%)$ & & $10(50 \%)$ & & \\
\hline 4 - 8 years & $2(10 \%)$ & & $\mathrm{I}(5 \%)$ & & \\
\hline 8 years or more & $13(65 \%)$ & & $9(45 \%)$ & & \\
\hline \multicolumn{6}{|l|}{ Hip Prosthesis } \\
\hline Right & $12(60 \%)$ & & $\mathrm{N} / \mathrm{A}$ & & \\
\hline Left & $8(40 \%)$ & & & & \\
\hline \multicolumn{6}{|l|}{ Surgery Complications } \\
\hline Yes & $2(10 \%)$ & & $\mathrm{N} / \mathrm{A}$ & & \\
\hline No & I8(90\%) & & & & \\
\hline Time of prosthesis use (Years) & $2.67(1.30)$ & $0.7-4.97$ & $\mathrm{~N} / \mathrm{A}$ & & \\
\hline \multicolumn{6}{|l|}{ PO Physical Therapy } \\
\hline Yes & $13(65 \%)$ & & $\mathrm{N} / \mathrm{A}$ & & \\
\hline No & $7(35 \%)$ & & & & \\
\hline
\end{tabular}

\footnotetext{
* Independent student's $t$ test for analyses between groups.
}

Mean values and (standard-deviation); values separated by - represents minimum and maximum limits.

BMI: body mass index.

\#Comorbidities consisted of diabetes, arterial hypertension, gastritis, glaucoma, hypercholesterolemy and hypothyroidism besides OA conditions.

$\mathrm{Kg}$, kilograms; Kg/m², kilogram per meter square; N/A, not applicable; PO, post-operative 
Table 2 WOMAC questionnaire outcomes for the THA group

\begin{tabular}{llll}
\hline WOMAC & & & \\
\hline Domains & Mean & Standard-deviation & $*$ Min-max \\
\hline Pain & 6 & 11,85 & $0-50$ \\
Stiffness & 8,12 & 15,39 & $0-50$ \\
Physical function & 9,12 & 20,45 & $0-100$ \\
\hline
\end{tabular}

*Min-Max, minimum and maximum limits.

There were no significant differences between the non-operated between groups showed decreased muscular performance in the THA and operated limbs in relation to peak torque normalized by body mass, elderly operated limbs for hip abduction, knee flexion and extension maximal work normalized by body mass and average power variables in all movements and at the different velocities (Table 3). Comparisons movements, at slow and fast velocities (Table 4).

Table 3 Results for muscular performance parameters: comparison between operated and non-operated limbs in the THA group

\begin{tabular}{|c|c|c|c|c|c|}
\hline Movement $\mathrm{v}=60 \% \mathrm{~s}$ & Hip & Peak torque (\%)\# & $\mathbf{p}$ & Maximal work (\%)\# & $\mathbf{p}$ \\
\hline \multirow[t]{2}{*}{ Extension(knee) } & NO & $149,18(33,55)$ & 0,158 & |49,03(37,78) & 0,208 \\
\hline & 0 & $139,05(32,55)$ & & $|39,8|(35,3 \mid)$ & \\
\hline \multirow[t]{2}{*}{ Flexion(Knee) } & NO & $62,72(15,54)$ & 0,397 & $63,64(19,66)$ & 0,912 \\
\hline & 0 & $59,9(22,41)$ & & $63,21(27,36)$ & \\
\hline \multirow[t]{2}{*}{ Abduction } & NO & $|08,7|(20,43)$ & 0,297 & $37,10(8,24)$ & $0,7 \mid I$ \\
\hline & $\mathrm{O}$ & II4,34(27,23) & & $37,89(10,73)$ & \\
\hline \multirow[t]{2}{*}{ Adduction } & NO & $101,5(37,79)$ & 0,644 & $24,92(13,14)$ & $0,25^{*}$ \\
\hline & $\mathrm{O}$ & $104,8(34,47)$ & & $26,08(11,06)$ & \\
\hline \multirow[t]{2}{*}{ Flexion } & NO & $|32,4|(25,55)$ & 0,655 & $96,57(21,56)$ & $0,73^{*}$ \\
\hline & $\mathrm{O}$ & $129,89(30,61)$ & & $95, \mathrm{I} I(24,64)$ & \\
\hline \multirow[t]{2}{*}{ Extension } & NO & $107,28(33,96)$ & 0,687 & $70,09(30,43)$ & $0,85^{*}$ \\
\hline & 0 & $109,17(33,88)$ & & $68,79(31,37)$ & \\
\hline Movement v $=120 \%$ e $180 \%$ & Hip & Peak torque (\%)\# & $\mathbf{p}$ & Average power (W) & $\mathbf{p}$ \\
\hline \multirow[t]{2}{*}{ Extension $180^{\circ} / \mathrm{s}($ knee $)$} & NO & $94,54(17,26)$ & 0,932 & $94,43(27,04)$ & 0,440 \\
\hline & $\mathrm{O}$ & $94,79(20,65)$ & & $97,64(35,36)$ & \\
\hline \multirow[t]{2}{*}{ Flexion $180^{\circ} / \mathrm{s}($ knee $)$} & NO & $44,43(9,93)$ & 0,820 & $38,04(16,65)$ & $0,97^{*}$ \\
\hline & O & $43,80(I I, 4 I)$ & & $37,72(19,3)$ & \\
\hline \multirow[t]{2}{*}{ Abduction $120 \%$ s } & NO & $74,66(24,56)$ & 0,607 & $37,21(16,16)$ & 0,708 \\
\hline & 0 & $76,98(29,79)$ & & $36,26(15,87)$ & \\
\hline \multirow[t]{2}{*}{ Extension $120 \%$} & NO & $106,81(39,8 I)$ & $0,85^{*}$ & $56,34(31,96)$ & $0,33^{*}$ \\
\hline & $\mathrm{O}$ & $106,64(43,47)$ & & $51,39(36,07)$ & \\
\hline \multirow[t]{2}{*}{ Flexion $120 \% / \mathrm{s}$} & NO & $|30,8|(25,3 \mid)$ & 0,069 & $88,4 I(22,8)$ & 0,663 \\
\hline & 0 & $120,94(31,27)$ & & $86,57(26,54)$ & \\
\hline
\end{tabular}

No significant differences were observed.

\#normalized by body mass.

ANOVA and wilcoxon* analyses.

$\mathrm{V}$, angular velocity; W, watts; O, operated; NO, non-operated 
Table 4 Results for muscular performance parameters: comparisons between THA elderly operated and matched control limbs

\begin{tabular}{|c|c|c|c|c|c|c|c|}
\hline Movement $\mathrm{v}=60 \% \mathrm{~s}$ & Hip & Peak torque (\%)\# & $\mathbf{p}$ & Power & Maximal work (\%)\# & $\mathbf{p}$ & Power \\
\hline \multirow[t]{2}{*}{ Extension(knee) } & THA & $139,05(32,55)$ & 0,000 & 0,992 & $|39,8|(35,3 \mid)$ & 0,000 & 1,000 \\
\hline & Con & $172,59(39,37)$ & & & $177,83(37,90)$ & & \\
\hline \multirow[t]{2}{*}{ Flexion(Knee) } & THA & $59,9(22,4 I)$ & 0,002 & 0,935 & $63,2 I(27,36)$ & 0,002 & 0,922 \\
\hline & Con & $79,6(26,28)$ & & & $83,38(25,94)$ & & \\
\hline \multirow[t]{2}{*}{ Abduction } & THA & II4,34(27,23) & 0,000 & 0,989 & $37,89(10,73)$ & 0,080 & 0,419 \\
\hline & Con & $138,3(3 \mid, 52)$ & & & $42,98(13,30)$ & & \\
\hline \multirow[t]{2}{*}{ Adduction } & THA & $104,8(34,47)$ & 0,191 & 0,251 & $26,08(11,06)$ & $0,491 *$ & 0,265 \\
\hline & Con & I I6,27(34,9) & & & $29,63(12,63)$ & & \\
\hline \multirow[t]{2}{*}{ Flexion } & THA & $129,89(30,61)$ & 0,164 & 0,279 & $95, \mathrm{I} I(24,64)$ & $0,37 *$ & 0,27 \\
\hline & Con & $|44,4|(3|| 5)$, & & & $104,78(25,37)$ & & \\
\hline \multirow[t]{2}{*}{ Extension } & THA & $109,17(33,88)$ & $0,37 *$ & $0,5 \mid 4$ & $68,79(31,37)$ & $0,18 *$ & $0,5 \mid 4$ \\
\hline & Con & $|3|, 83(45,73)$ & & & $78,98(31,58)$ & & \\
\hline Movement $v=120 \% / \mathrm{s}$ e $180 \% / \mathrm{s}$ & Hip & Peak torque (\%)\# & $\mathbf{p}$ & Power & Average power (W) & $\mathbf{p}$ & Power \\
\hline \multirow[t]{2}{*}{ Extension $180 \%$ s(knee $)$} & THA & $94,79(20,65)$ & 0,000 & 0,984 & $97,64(35,36)$ & 0,002 & 0,928 \\
\hline & Con & $115,76(31,63)$ & & & $120,99(4 \mid, 6)$ & & \\
\hline \multirow[t]{2}{*}{ Flexion $180^{\circ} / \mathrm{s}(\mathrm{knee})$} & THA & $43,80(I I, 4 I)$ & 0,002 & 0,926 & $37,72(19,3)$ & $0,002 *$ & $0,92 *$ \\
\hline & Con & $56,55(17,37)$ & & & $54,74(24,3)$ & & \\
\hline \multirow[t]{2}{*}{ Abduction $120 \% / \mathrm{s}$} & THA & $76,98(29,79)$ & 0,008 & 0,798 & $36,26(15,87)$ & 0,030 & 0,608 \\
\hline & Con & $98,88(32,37)$ & & & $48,02(18,76)$ & & \\
\hline \multirow[t]{2}{*}{ Extension $120 \%$} & THA & $120,94(3 \mid, 27)$ & 0,393 & 0,132 & $86,57(26,54)$ & 0,438 & 0,117 \\
\hline & Con & $134,78(35,23)$ & & & $93,87(34,16)$ & & \\
\hline \multirow[t]{2}{*}{ Flexion $120^{\circ} / \mathrm{s}$} & THA & $106,64(43,47)$ & 0,23 & 0,22 & $51,39(36,07)$ & $0,37 *$ & $0,34 *$ \\
\hline & Con & $121,52(45,02)$ & & & $68,64(42,06)$ & & \\
\hline
\end{tabular}

Mean, standard-deviation ( ), $\mathrm{p}$ and power values.

\#normalized by body mass

ANOVA and friedman* analyses.

$\mathrm{V}$, angular velocity; $\mathrm{W}$, watts; Con, control

At the self-selected gait speed, no difference between groups was observed $(\mathrm{THA}=1.28 \mathrm{~m} / \mathrm{s}$, Control $=1.34 \mathrm{~m} / \mathrm{s}, \mathrm{p}=0.47)$. But at the maximal gait speed (Figure 1) significant difference between groups was observed. Maximal gait speed was significantly lower in the THA group, $\mathrm{p}=0.017$. The Pearson's correlation did not show association between the maximal work normalized by body mass and the time of prosthesis use (years) for all movements and velocities ( $p>0.20)$ (data not showed). It indicates that the elderly who have more time since surgery don't necessarily have greater strength compared with those who have less time of prosthesis.

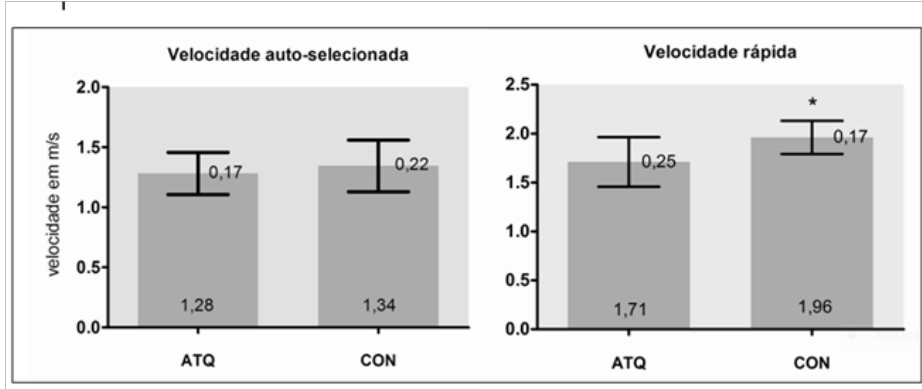

Figure I Self-selected and maximal gait speeds by group, normalized by the leg length.

*significantly upper than THA group, $p=0,017$ (ANOVA).

Citation: Borges VS, Domingues JM, Dias RC, et al. Muscular and functional performance measurement is reduced in elderly after total hip arthroplasty: an observational study. Int Phys Med Rehab J. 20I7;2(3):224-23 I. DOI: I0.I5406/ipmrj.20I7.02.0005 I 


\section{Discussion}

The results of this study have identified quantitative differences in isokinetic muscular function and fast gait speed, in THA elderly as compared with a control group, without prosthesis but presenting similar characteristics. Despite the differences between groups, there were no observed decreases in muscular performance parameters in the THA group (non-operated limb versus operated). The self-selected gait speed measurement did not show differences between groups. At the postoperative period that the elderly were evaluated ( 8 months to 5 years), lower scores of WOMAC questionnaire were observed. The weak correlation between the time of prosthesis and the maximal work normalized by body mass for all movements and angular velocities showed that there was no relation between the muscular performance and the time of prosthesis.

The isokinetic dynamometer was the device used in this study to evaluate the muscular performance parameters (peak torque and maximal work normalized by body mass and average power). It is considered an appropriate instrument to detect changes in the muscular performance of hip flexor, extensor, adductor and abductor, and knee flexor and extensor, in elderly who have undergone THA surgery. ${ }^{14,19,21,31}$ Besides being a safe equipment, the elderly were evaluated 8 months to 5 years after surgery, a time period where the muscle and bone tissue healing is completed, minimizing the risks during the tests. ${ }^{15,19}$ The matching between groups by age, gender, dominant limb and BMI seemed to be effective to assure group similarity, because these variables have strong relation to the muscular performance.

Although previous studies ${ }^{19,21,31}$ have evaluated the muscular performance of elderly who underwent THA, the time of post-operative did not overtake 5 months and none of these studies evaluated so many muscle groups as the present one. Besides, the hip measurements were not carried out in standing position ${ }^{14,19,31}$ however the majority of hip functional movements is performed in orthostatism. ${ }^{35}$ Moreover, these previous studies evaluated the intervention effects ${ }^{14}$ before and after the surgery procedure without comparing with a matched control group without prosthesis. . $^{21,31,39}$

In the study by Bertucci et al. ${ }^{19}$ they did not find differences in strength and power of hip flexor, extensor and abductor muscles when non-operated and operated limb were compared. The authors justified the results based on the mobility and functional limitations imposed by the operated hip that resulted in muscular hypotrophy in the nonoperated hip, due to less use of this limb. However, when comparing with the elderly without THA, but similar in gender and number of comorbidities these differences were observed in all movements assessed.

In the present study, the muscular performance parameters of hip flexion and extension movements were not different between groups. It could be justified by the insufficient number of participants revealed by the statistical power analysis. Rossi et al. ${ }^{31}$ assessed hip extensor and flexor torque production in individuals with hip osteoarthritis before the THA and 60 days after the surgery. The involved side was very weak as compared with the uninvolved side before surgery, but in the second evaluation there was no difference. Studies documenting the individual's ability to generate torque production of the involved hip ${ }^{31}$ and $\mathrm{kne}^{21}$ joint musculature before arthroplasty are limited. In the study by Shih et al..$^{40}$ where hip flexor, extensor and abductor muscles were tested in the isometric mode one year after THA surgery, only the hip flexors showed decrease in strength parameters.
In the present study, the hip abductor muscular performance parameters of the THA group were inferior compared with the control group. These muscles, especially the gluteus medius, have the function of stabilizing the pelvis on frontal plane, playing an important role in the balance control and gait. ${ }^{17,41}$ The elderly hip abductor torque integrity is essential to lateral stability, mainly in situations requiring rapid torque production with a critical time period. ${ }^{17}$ The aging process changes the torque production ability, explained by sarcopenia, type II muscle atrophy, or other physiologic phenomena. ${ }^{4,17}$ The capability to generate torque in elderly woman decline more than $40 \%$ for both hip abduction and adduction. ${ }^{17}$ In joint deformity conditions, as osteoarthritis, the results are even worse. ${ }^{4,21,31}$ And after surgery, the hip muscular atrophy could remain until two years after the procedure, providing reduced protection of the implant. ${ }^{39}$

There is a strong biomechanics relationship between hip and knee joints. ${ }^{21,42,43}$ Decrease in hip abductor strength, increase the medial load on ipsilateral medial knee, potentially increase the likelihood of medial knee $\mathrm{OA} .{ }^{42}$ As a compensatory mechanism, the existing alteration on the knee joint can reduce the knee extensor strength and increase the hip extension strength caused by abnormal knee kinematic ${ }^{43}$ Amaro et al. ${ }^{41}$ discussed the maintenance of abductor structure and function of both hips, indicating that the weakness of abductor muscle fibers could be of etiological importance in the development or progression of hip OA.

The study of Aroskoski et al. ${ }^{4}$ showed that the hip isometric and isokinetic extension torques did not differ when the OA group was compared with a control group. In the present study, even excluding elderly with knee and hip OA, articular degenerative processes affecting these joints without participant's knowledge could have been the etiologic factors of the reduced knee extensor and flexor torque, work and power and the maintenance of these parameters in hip extensor movements.

Employing similar characteristics as the present study, Suetta et al. ${ }^{21}$ evaluated the knee flexor and extensor peak torque in the elderly before and after THA. After 12 weeks, the peak torque increased on the operated side, in the group who participated in resistance training, $28 \%$ and $22 \%$ at the preset angular velocities $(60 \%$ s and $180 \%$ s). In contrast, Reardon et al. ${ }^{44}$ demonstrated significant atrophy of the ipsilateral quadriceps muscle which persisted at 5 months follow-up, despite physical rehabilitation.

Months and years after surgery, the elderly of the present study showed lower values of peak torque, maximal work and average power of the knee flexor and extensor muscles, at the preset angular velocities measured, when compared with the control group. In another study, the quadriceps cross-sectional area in the group who received standard rehabilitation (exercises without resistance), decreased on the operated side 12 weeks after surgery. ${ }^{21}$ This decreasing could justify the results found in the present study, because maximal muscle strength is directly related to muscle integrity components. ${ }^{4,21}$ As an inclusion criterion, the posterolateral approach was the procedure investigated in the present study. There is a long debate about the best surgery procedure, however this issue is controversial and the results are inconclusive regarding the merit of the best approach $[15,45]$. Maffiuletti et al..$^{15}$ investigated the spatiotemporal parameters of gait in two elderly groups, following different THA surgery procedures and compared with a group of age-matched individuals. At maximal gait speed, significantly lower speed in the THA group than in control group was observed. Similar findings were observed in the present study, with no significant main effect between groups at self-selected 
gait speed. Isokinetic muscular performance deficits may contribute to impairment in postural stability and affect gait patterns, even when there is no pain..$^{19,39,40}$

Walking speed is an important indicator of functionality, its assessment is simple, and has been essential to clinical practice. ${ }^{30,46}$ The effective elderly ability in modulating their gait speed is a necessary and safe strategy, mainly when talking about a functional environment, for example crossing the street. This way, problems in increasing the step length and the cadence to accelerate the gait, may generate balance alterations and risk of falls..$^{30,43}$

In the present study, the THA group showed lower values for peak torque and power of the hip abductor and knee flexor and extensor musculature. These findings may negatively influence the maximal gait speed outcome. ${ }^{17,41}$ In accordance with other studies. ${ }^{8,15,47}$ lower scores in the WOMAC domains were observed. It shows that elderly who underwent THA can experience excellent health condition, evaluated by pain, stiffness and physical function subscale scores. WOMAC is a reliable, valid and responsive questionnaire to detect changes after THA. ${ }^{27}$ One year after THA surgery, patients achieve $50 \%$ improvement in WOMAC scores. ${ }^{8}$

One limitation of this study was the poor investigation of the activity level, because even including elderly who did not practice physical activity, the lifestyle could be an influence factor in the motor performance parameters. It was a cross-sectional study, meaning causal conclusions were not allowed. The time period of OA diagnosis was not investigated, it could contribute to adverse effects at the state of recovery. ${ }^{4}$ Data about physical therapy rehabilitation after surgery was recorded, but there was not a control about the rehabilitation source and period of time, and the inclusion of elderly who had not done physical therapy.

Despite its limitations, is important to highlight the methodological control followed in this study. It includes the training of the investigator responsible for assessments; the intra-examiner reliability testing; the inclusion of an appropriate matched control group and a methodical inclusion of the THA group. These procedures might ensure the outcomes and give support for the conclusions of the study.

\section{Acknowledgements}

None.

\section{Conflict of interest}

The authors have not supplied their declaration of competing interest.

\section{References}

1. Chaimowicz F. A saúde dos idosos brasileiros às vésperas do século XXI: problemas, projeções e alternativas. Rev Saúde Pública. 1997;31(2):184 200 .

2. Camarano AA. Envelhecimento da população brasileira: uma contribuição demográfica. Instituto de Pesquisa Econômica Aplicada, Rio de Janeiro. Brazil; 2002. p. 1-31.

3. Altman R, Alarcon G, Appelrouth D, et al. The american college of rheumatology criteria for the classification and reporting of osteoarthritis of the hip. Arthritis Rheum. 1991;34(5):505-514.

4. Arokoski MH, Haara M, Helminen HJ, et al. Physical function in men with and without hip osteoarthritis. Arch Phys Med Rehabil. 2014;85(4):574-581.
5. Felson DT. Epidemiology of hip and knee osteoarthritis. Epidemiol Rev. 1998;10:1-28.

6. Zhang W, Doherty M, Arden N, et al. EULAR evidence based recommendations for the management of hip osteoarthritis: report of a task force of the EULAR Standing Committee for International Clinical Studies Including Therapeutics (ESCISIT). Ann Rheum Dis. 2005;64(5):669-681.

7. Lanyon P, Muir K, Doherty S, et al. Assessment of a genetic contribution to osteoarthritis of the hip: sibling study. BMJ. 2000; 321(7270):11791183.

8. Hamel MB, Toth M, Legedza A, et al. Joint replacement surgery in elderly patients with severe osteoarthritis of the hip or knee: decision making, postoperative recovery and clinical outcomes. Arch Intern Med. 2000;168(13):1430-1440.

9. Iorio R, Robb WJ, Healy WL, et al. Orthopaedic surgeon workforce and volume assessment for total hip and knee replacement in the United States: preparing for an epidemic. J Bone Joint Surg Am. 2008;90(7):1598-1605.

10. Hugh GA, Luker KA, Campbell M, et al. Pain, physical functioning and quality of life of individuals awaiting total joint replacement: a longitudinal study. J Eval Clin Pract. 2008;14(1):19-26.

11. Ricci NA, Coimbra IB. Exercício físico como tratamento na osteoartrite de quadril: uma revisão de ensaios clínicos aleatórios controlados. Rev Bras Reumatol. 2006;46(4):273-280.

12. Dougados M, Gueguen A, Nguyen M, et al. Radiological progression of hip osteoarthritis: definition, risk factors and correlations with clinical status. Ann Rheum Dis. 1996;55(6):356-362.

13. Quintana JM, Bilbao A, Escobar A, et al. Decision trees for indication of total hip replacement on patients with osteoarthritis. Rheumatology. 2009;48(11):1402-1409.

14. Sashika H, Matsuba Y, Watanabe Y. Home program of physical therapy: effect on disabilities of patients with total hip arthroplasty. Arch Phys Med Rehabil. 1996;77(3):273-277.

15. Maffiuletti NA, Impellizzeri FM, Widler K, et al. Spatiotemporal parameters of gait after total hip replacement: anterior versus posterior approach. Orthop Clin North Am. 2009;40(3):407-415.

16. Frontera WR, Reid KF, Phillips EM, et al. Muscle fiber size and function in elderly humans: a longitudinal study. J Appl Physiol. 2008;105(2):637642.

17. Johnson ME, Mille ML, Martinez KM, et al. Age-related changes in hip abductor and adductor joint torques. Arch Phys Med Rehabil. 2004;85(4):593-97.

18. Lossing WI, Grimby G, Jonsson T, et al. Effects of electrical muscle stimulation combined with voluntary contractions after knee ligament surgery. Med Sci Sports Exerc. 1988;20(1):93-98.

19. Bertocci GE, Munin MC, Frost KL, et al. Isokinetic performance after total hip replacement. Am J Phys Med Rehabil. 2004;83(1):1-9.

20. Cohen J. Statistical Power for the Behavioral Sciences. USA: Academic Press; 1977. 490 p.

21. Suetta C, Magnusson SP, Rosted A, et al. Resistance training in the early postoperative phase reduces hospitalization and leads to muscle hypertrophy in elderly hip surgery patients-a controlled, randomized study. J Am Geriatr Soc. 2004;52(12):2016-2022.

22. Brucki SMD, Nitrini R, Caramelli P, et al. Sugestões para o uso do mini-exame do estado mental no brasil. Arq Neuro-Psiquiatr. 2003;61(3B):777-781. 
23. Triagem de Saúde e Estratificação dos Riscos. American College Of Sports Medicine Diretrizes do ACSM para os testes de esforço e sua prescrição. Brazil: Guanabara Koogan; 2003. p. 15-21.

24. System 3 Pro: Application Operation Manual Version 3; 2009.

25. GAITRite Manual Version Version 3.9; 2009.

26. Fernandes MI, Ferraz MB, Ciconelli RM. Tradução e validação do questionário de qualidade de vida específico para osteoartrose (WOMAC) para a língua portuguesa. Rev Paul Reumatol. 2002;10:25.

27. Bellamy N, Buchanan WW, Goldsmith $\mathrm{CH}$, et al. Validation study of WOMAC: a health status instrument for measuring clinically important patient relevant outcomes to antirheumatic drug therapy in patients with osteoarthritis of the hip or knee. J Rheumatol. 1988;15(12):1833-1840.

28. Beauchet O, Annweiler C, Lecordroch Y, et al. Walking speed-related changes in stride time variability: effects of decreased speed. $J$ Neuroeng Rehabil. 2009;6:32.

29. Vasconcelos KSS, Dias JMD, Dias RC. Relação entre intensidade de dor e capacidade funcional em indivíduos obesos com osteoartrite de joelho. Rev Bras Fisioter. 2006;10(2):213-218.

30. Menz HB, Latt MD, Tiedemann A, et al. Reliability of the GAITRite walkway system for the quantification of temporo-spatial parameters of gait in young and older people. Gait Posture. 2004;20(1):20-25.

31. Rossi MD, Brown LE, Whitehurst MA. Assessment of hip extensor and flexor strength two months after unilateral total hip arthroplasty. $J$ Strength Cond Res. 2006;20(2):262-267.

32. Perrin DH. Isokinetic Exercise and Assessment. USA: Human kinetics publishers; 1993.

33. Davies GJ. A compendium of isokinetics in clinical usage and rehabilitation techniques.: USA: S, S Publishers; 1987. p. 530.

34. Nair PJ, Depledge J, Brettkelly $M$, et al. Verbal encouragement: effects on maximum effort voluntary muscle action. Br J Sports Med. 1996;30(3):243-245

35. Lockwood J. Isokinetic: Muscles testing, interpretation and clinical applications. Physiotherapy. 1996;82(2):142.
36. Johnson ME, Mille ML, Martinez KM, et al. Age-related changes in hip abductor and adductor joint torques. Arch Phys Med Rehabil. 2004;85(4):593-597.

37. Oliveira A. Estudo comparativo do desempenho muscular isocinético do quadril de jovens e idosos utilizando um dispositivo estabilizador Universidade Federal de Minas Gerais: Brazil; 2006.

38. Cahalan TD, Johnson ME, Liu S, et al. Quantitative measurements of hip strength in different age groups. Clin Orthop Relat Res. 1989;(246):136145

39. Jackson TE, Emerson R, Smith S. Outcomes of total hip arthroplasty: a study of patients one year postsurgery. J Orthop Sports Phys Ther. 2002;32(6):260-267.

40. Shih $\mathrm{CH}, \mathrm{Du} \mathrm{YK}$, Lin $\mathrm{YH}$, et al. Muscular recovery around the hip joint after total hip arthroplasty. Clin Orthop Relat Res. 1994;(302):115-120.

41. Amaro A, Amado F, Duarte JA, et al. Gluteus medius muscle atrophy is related to contralateral and ipsilateral hip joint osteoarthritis. Int J Sports Med. 2007;28(12):1035-1039.

42. Chang A, Hayes K, Dunlop D, et al. Hip abduction moment and protection against medial tibiofemoral osteoarthritis progression. Arthritis Rheum. 2005;52(11):3515-3519.

43. Gibbon CA, Krebs DE. Compensatory gait mechanics in patients with unilateral knee arthritis. J Rheumatol. 2002;29(11):2410-2419.

44. Reardon K, Galea M, Dennett X, et al. Quadriceps muscle wasting persists 5 months after total hip arthroplasty for osteoarthritis of the hip: a pilot study. Intern Med J. 2001;31(1):7-14.

45. Downing ND, Clark DI, Hutchinson JW, et al. Hip abductor strength following total hip arthroplasty: a prospective comparison of the posterior and lateral approach in 100 patients. Acta Orthop Scand. 2001;72(3):215-220.

46. Donough AL, Batavia M, Chen FC, et al. The validity and reliability of the GAIT Rite system's measurements: A preliminary evaluation. Arch Phys Med Rehabil. 2001;82(3):419-425.

47. Jandric S, Manojlovic S. Quality of life of men and women with osteoarthritis of the hip and arthroplasty: assessment by WOMAC questionnaire. Am J Phys Med Rehabil. 2009;88(4):328-335. 